\title{
Roma y Netflix: ganando premios y rompiendo reglas
}

\author{
Fernando Moreno Suárez
}

Universidad Iberoamericana, México

\begin{abstract}
Five years after his International consecration in the 86th American Motion Picture Academy awards, in which his film 'Gravity' rose with 7 Oscar awards, Mexican filmaker Alfonso Cuarón keeps gaining atention and winning prizes with his new movie 'Roma'.

Shooted entirely in Mexico, the 8th movie of this Mexico City born and raised filmaker is much more that a return to his homeland, it has become an innovative case, critic and distribution wise, that deserves analysis.

Heightened within a context in which cinema produced in Mexico has a complicated distribution and a nearly impossible exhibition conditions (only half of the over 150 local industry produced pictures are shown in theatres), Roma commercial release has been, to say the less, successful, a paradox and certainly unique, being on Netflix as its main distribution platform.

Winner of three Oscar awards this past February (Best Foreign Language film, Best Director, Best cinematography) with 10 nominations, and winner of Best Picture at the British BAFTA awards, and laurate of prestigious film festivals as Venice, Roma is financed by Netflix and with a distribution contract on this streaming platform, that has confronted two business models that is changing the industry irretrievably.
\end{abstract}

Keywords: Mexican Cinema, Production, Exhibition, Distribution, Streaming

No es cierto mucho de lo que se dice de la globalización. Por ejemplo, que uniforma a todo el mundo. Ni siquiera ha conseguido que exista una sola definición de lo que significa globalizarse...

Néstor García Canclini, "La globalización imaginada”.

\section{Introducción}

Cinco años después de su consagración internacional en la 86 entrega de los premios de la Academia Norteamericana de cine, donde su película Gravedad se alzó con siete premios Óscar, el cineasta mexicano Alfonso Cuarón sigue llamando la atención y ganando premios, ahora con su nueva cinta Roma.

Filmada completamente en su país, la octava película del realizador nacido en la Ciudad de México es mucho más que su regreso a su tierra natal y ha significado, sobre todo a nivel de crítica y distribución, un caso muy especial que merece estudio y análisis.

Enmarcado en un entorno en el que el cine producido en México tiene una distribución complicada y una exhibición incipiente el estreno comercial de Roma ha sido, por decir lo menos, exitoso, paradójico y único al mismo tiempo, al apostar por las ventanas digitales y las plataformas de streaming como una de sus estrategias principales para conectar con el público.
Ganadora de tres Óscares el 24 de febrero de este año (Mejor película en lengua extranjera, Mejor director y Mejor fotografía), y de los premios principales de certámenes tan prestigiosos como el de Venecia, Roma, producida por Participant Media, Pimienta Films y Esperanto Filmoj, y con un acuerdo de distribución con la plataforma de streaming Netflix incluso antes de su corrida en festivales, significa también un hito histórico en el que dos modelos de negocio se enfrentan mientras la industria cinematográfica cambia irremediablemente.

Por un lado están las grandes compañías productoras y las cadenas de exhibición y distribución tradicionales. Por el otro, los nuevos medios que, a través del streaming y sus nuevos modelos de financiamiento, producción, exhibición y distribución, y su contacto directo con sus usuarios, intentan cambiar las reglas del juego. Un choque de trenes y visiones que dará mucho de que hablar en los próximos años y que, en el mejor de los casos, significará un reacomodo entre los participantes de lo que se ha llegado a llamar la ecología mediática global.

De todas las circunstancias especiales en el caso de Roma, y de esas particularidades, trata este texto.

\section{México como escenario. La industria como contexto.}

Lo primero que vale la pena aclarar al hablar de México como mercado cinematográfico, es que su realidad en cuanto a consumo y producción de películas no tiene mucho que ver con el tamaño de la economía de la nación ni del lugar, tamaño o importancia que ocupan las finanzas locales en el concierto internacional.

Reconocido globalmente como una potencia fílmica, las estadísticas que arrojan los reportes del 2018 de CANACINE (Cámara Nacional de la Industria Cinematográfica) sitúan al país como un mercado de 16,810 millones de pesos (CANACINE 2018, 3) que vendió 332 millones de boletos (CANACINE, 2018, 4) en el ejercicio anterior -cuarto lugar mundial en el rubro sólo detrás de India, China y Estados Unidos, en el cual se llegó al número récord de 7,106 salas (CANACINE 2018, 24) -también cuartos a nivel mundial con 513 nuevas pantallas construidas en los últimos 12 meses (CANACINE 2018, 25).

En las pantallas mexicanas se estrenaron en 2018 la cifra de 487 películas, de las cuales 116 fueron producciones locales, 188 procedentes de la industria norteamericana y 199 del resto del mundo (CANACINE $2018,15)$. La gravedad de los números de la exhibición en México se revela cuando revisamos el porcentaje de esa participación en pantalla que se limita un $8.3 \%$ de las ganancias en la taquilla total (CANACINE 2018, 13). Así, aunque la producción esté en un aumento constante y la cantidad de boletos vendidos también 
siga creciendo -29.5 millones (CANACINE 2018,12)-, las películas mexicanas no terminan por beneficiarse realmente de las ramas de la industria en distribución y exhibición que gozan de cabal salud. Como muestra de esto bastan un par de botones: el primero tiene que ver con los resultados ya que ninguna película producida en el país formó parte de la lista de las mas vistas en el año. El segundo consiste en comparar los números de la cinta más exitosa del periodo, Avengers Infinity War con 21.5 millones de entradas vendidas (CANACINE 2018, 7), con la mexicana que consiguió mejores resultados: Ya veremos, con 4.1 millones de asistentes (CANACINE 2018, 10).

$\mathrm{Si}$ a lo anterior sumamos algunos datos sobre el panorama de las plataformas de streaming en territorio mexicano, podremos entender un poco mas lo que puede llegar a implicar el caso de Roma que estamos revisando.

Según la consultora The Competitive Intelligence Unit (CIU) el servicio de televisión de paga por internet, conocido también como OTT (Over the Top), alcanzará en el país para finales de 2019 los 53.6 millones de usuarios. De ellos, la empresa favorita para los mexicanos es hoy Netflix que alcanza un $80 \%$ de los suscriptores, seguido por Claro Video con 14\%, Blim con $2.7 \%$ y HBO GO con $1.5 \%$. (Martínez 2019)

\section{Los orígenes de Roma: de la calle Tepeji a Hollywood.}

Siempre resulta mas sencillo mirar las cosas con la perspectiva que nos aporta el tiempo pero, lo que parece cierto al menos en el caso de la cinta Roma, octavo largometraje del cineasta mexicano Alfonso Cuarón (Ciudad de México, 1961), es que su historia se remonta a la infancia del realizador a inicios de los años setenta en la capital de país. En esa línea temporal, y también en un espacio geográfico delimitado, el niño que se convertiría en cineasta creció en la colonia Roma, un barrio de clase media de la Ciudad de México que daría, casi cuarenta años después, atmósfera y título a su más reciente largometraje.

Después de una exitosa carrera que comenzó en su país natal en 1991 con el filme Sólo con con tu pareja -que le significó cuatro nominaciones al Ariel de la Academia de Ciencias Artes Cinematográficas de México y el premio al mejor guión original-, el recorrido de veintisiete años del director lo ha llevado a filmar cintas lo mismo en la industria norteamericana -La princesita, 1995; Grandes esperanzas, 1998- que en la británica -Hijos del hombre, 2006-, a realizar proyectos con los grandes estudios como Warner -en cintas como Harry Potter y el prisionero de Azkaban, 2004-, o a escribir y contar historias eminentemente personales -como Y tu mamá también, 2001-.

A lo largo de toda esta trayectoria, y a fuerza de construir un prestigio de autor ganado a pulso, Cuarón parecía llegar a su punto más alto en la entrega 86 de los premios de la academia norteamericana en los que su cinta Gravedad (2013) se alzó con siete Óscares. Entre ellos, el de mejor director para él, con el que se convertía así en el primer cineasta latinoamericano en recibir esa distinción.

Después de esa noche, y de su rotundo triunfo con Gravedad, que resultaría el preámbulo de un éxito continuado para directores mexicanos que ganarían el premio de la academia americana cuatro de los siguientes cinco años (dos veces Alejandro González Iñárritu por Birdman en 2015 y El renacido en 2016, una Guillermo Del Toro por La forma del agua en 2018 y otra de nuevo para el propio Cuarón con Roma en la entrega de 2019), el realizador se enfrentaba a la encrucijada que reta a casi todos los cineastas que alcanzan el triunfo en Hollywood y tienen que seleccionar su próximo proyecto.

El más evidente de los caminos parecía llevarlo a acceder a grandes presupuestos y rodar películas cada vez mas ambiciosas en tamaño, inversión y búsqueda de audiencias. El otro, y por el cual terminó decantándose, tenía que ver con seguir sus instintos y hacer su película más personal y compleja. Recuperar del olvido una colección de recuerdos de infancia y sacar del cajón aquel guion escrito hacía tiempo sobre el México de los setenta y su conformación política y social. Filmar una película sobre una familia de clase media capitalina en blanco y negro, hablada en castellano y mixteco -una lengua indígena originaria del estado de Oaxaca en el sureste de México- que, difícilmente, resultaría atractiva para las grandes productoras y estudios de primera línea que intentarían convencer a uno de los directores mas en forma de la industria global a que trabajara con ellos.

Lo que nadie esperaba es que, justo con esa fórmula, a la que sumaría una arriesgada combinación de actores no profesionales y desconocidos con intérpretes con una basta experiencia en teatro; y con una propuesta narrativa llena de planos secuencias y ritmo hipnótico, Alfonso Cuarón conseguiría una de las películas mas importantes de la década, y un éxito de crítica y público sin precedentes.

\section{El rodaje y los primeros acuerdos con Netflix.}

Alfonso Cuarón rodó Roma en locaciones de la Ciudad de México en el otoño de 2016 durante 19 semanas. El plan de trabajo y la organización de la producción partieron de premisas bastante peculiares. La dinámica tenía que ver con realizar las secuencias del proyecto en el orden cronológico en el que se desarrollan en la historia, por lo que que nadie dentro del equipo conocía el libreto completo, ni a detalle, al inicio de los trabajos de filmación. Sus colaboradores, lo mismo el director de arte que los actores, iban conociendo día a día lo que rodarían y el contenido de cada escena a trabajar. Esto implicaba que sólo el director, quién también fue el responsable de la redacción del guion, sabía el desenlace de la trama del filme, ni siquiera los productores, algo fuera de lo común en los estándares de trabajo del cine actual.

Para el mes de abril de 2017, antes de que se terminara la etapa de rodaje, los productores de la cinta (los ya citados Participant Media, Pimienta 
Films y Esperanto Filmoj) anunciaron un acuerdo de distribución con la plataforma de streaming Netflix que se encargaría de distribuir la cinta alrededor del mundo.

A partir de ese momento, y ante el interés de los productores de la cinta de presentarla en el concurso por la Palma de Oro del Festival internacional de cine de Cannes, comenzó una carrera contra el tiempo que llevaría a Roma a promover una serie de pláticas y gestiones que la pondría en el centro de las conversaciones cinematográficas más interesantes del año.

Sobre este asunto cabe señalar que existía un precedente en el concurso por la Palma de Oro de 2017, cuando un par de cintas que contaban con el logotipo de Netflix en su tira de créditos iniciales se habían colocado en el prestigioso certamen francés. Los títulos en cuestión son Okja del Sud coreano Boon Joon Hoo y The Meyerowitz stories de Noah Baumbach que, tras formar parte de la selección oficial del importante evento francés, levantaron una sonada polémica pues no se estrenarian en cines franceses e irían directo a la plataforma de streaming para su distribución. Un sencillo hecho que, enfrentaría de una manera que hasta hoy ha resultado irreconciliable, al festival -que prestó oídos y apoyó las quejas de los distribuidores y exhibidores franceses- $y$ a Netflix y su nueva manera de hacer llegar los contenidos a los espectadores.

En ese sentido conviene resaltar que, hasta hace unos meses que el Ministro de Cultura francés Franck Riester anunció un acuerdo entre la CNC (Centre National du Cinema et de l'Image Animée) y los operadores de TV de paga para reducir las ventanas tras un estreno comercial, una película que se estrenaba en una sala de cine en tierras galas debía esperar 36 meses para poder explotarse en una plataforma televisiva o digital. Desafortunadamente, el nuevo convenio reduce la espera apenas a 17 meses, lo cual sigue sin parecer conveniente a los que buscan explotar los contenidos a través de televisión de paga o video bajo demanda.

Con todos esos antecedentes, y aun a sabiendas que la nueva cinta de Alfonso Cuarón era un apetitoso plato fuerte para su festival, el director artístico de Cannes, Thierry Fremaux, y el director de contenidos de Netflix, Ted Sarandos, no consiguieron llegar a un acuerdo y Roma tuvo que buscar otros horizontes para empezar su recorrido para escribir su propia historia. Como resultado del desencuentro, y lejos de la impresión inicial que podría hacer parecer la ausencia de Roma en el concurso por la Palma de Oro como algo negativo, en términos mediáticos la discusión puso a la cinta en el centro de la conversación y le representó una publicidad gratuita particularmente útil.

\section{Venecia y el León de Oro: una campaña hecha a medida.}

Después del primer enfrentamiento entre dos maneras de entender el cine en nuestros días, $y$ tras la negativa de parte del Festival de Cannes para incluir a Roma en el concurso, Cuarón y sus socios encontraron en el Festival de cine de Venecia, el más antiguo del mundo y uno de los más prestigiosos según la FIAPF (Federación Internacional de Asociaciones de Productores de Films, por sus siglas en francés) que lo incluye en su lista de certámenes triple $\mathrm{A}$, un lugar ideal para hacer su premier mundial.

La primera proyección de la cinta tuvo lugar el 30 de agosto de 2018 en la Sala Grande en el marco de la Biennale di Venezia. La recepción, particularmente cálida, se tradujo en una ovación de pie del público asistente de siete minutos reportada como muy merecida por la prensa internacional. Tras esa primera buena impresión, siguieron una serie de éxitos de crítica que empezaron a catalogar el mas reciente largometraje del cineasta mexicano como una obra maestra y un clásico moderno instantáneo.

Si bien es cierto que nunca sabremos que hubiera pasado con Roma en el concurso de Cannes de ese año, en el que se levantaron con los premios pesos pesados del cine global como Hirokazu Kore Eda (Un asunto de familia), Pawel Pawlikowski (Cold War) o Spike Lee (Blakkklansman), lo que si sabemos es que alzarse en Venecia con el León de oro a mejor película, primera vez en la historia del evento para una cinta mexicana, catapultó al largometraje a un exitoso recorrido por festivales y pantallas de todo el mundo.

Tras la negativa de Cannes, el equipo de la cinta se puso a trabajar y orquestó una detallada campaña de comunicación y proyecciones que no dejó nada a la improvisación. Al estreno mundial en Venecia le siguió, solo un día después, el estreno continental en América en el Festival de cine de Telluride en Colorado y dos proyecciones privadas en el cine Tonalá de la Ciudad de México, el 1 y 3 de septiembre. Estas últimas harían a la producción elegible para representar a México en la categoría de mejor película extranjera en la entrega de los Óscares.

Muy poco después, el 8 de septiembre, específicamente, Roma gana el León de oro en Venecia y a eso le siguen proyecciones exitosas en Toronto -donde la película es acompañada por una exposición de objetos y decorados utilizados durante el rodaje-, San Sebastián y Nueva York.

\section{Roma en México.}

En territorio mexicano caben destacar tres iniciativas especialmente interesantes alrededor de presentaciones de Roma en las semanas siguientes. La primera tiene que ver con su presentación en el estado de Chiapas, al sureste del país y en la zona de influencia del Ejército Zapatista de Liberación Nacional, en el Festival de Puy ta Cuxlejaltic en el Caracol de Oventic. La segunda, con la asistencia del director, los actores y buena parte del equipo creativo y técnico, tuvo lugar en el Festival de Cine de Morelia, hoy por hoy el certamen mas prestigioso del calendario cinematográfico mexicano. Y la tercera, con un carácter particularmente simbólico, en el helipuerto del Centro Cultural Los Pinos, un lugar que, hasta una semana antes de la presentación de la cinta, operaba como residencia del presidente de la República y que recién se abría por iniciativa de la nueva administración a los 
ciudadanos como un espacio para el esparcimiento y la divulgación artística.

A todo lo anterior seguirían tiempos de premios, expectativas y confrontación.

Calificar a una cinta como la película del año, como fenómeno mediático o como éxito de crítica es algo que no le hace justicia a Roma.

Al León de Oro de Venecia, los tres Óscares de la Academia de Hollywood (Mejor cinta en lengua extranjera, Mejor director y Mejor fotografía), los cuatro premios BAFTA de la Academia Británica (Mejor película, Mejor película en lengua extranjera, Mejor fotografía y Mejor director) y los dos Globos de Oro (Mejor cinta en lengua extranjera y Mejor director), hay que sumar 170 premios internacionales más y otras tantas nominaciones en festivales alrededor del mundo. Para cerrar el inventario de reconocimientos, al menos por el momento, es necesario agregar las 15 nominaciones que recibió la cinta a los premios Ariel de la Academia Mexicana de Ciencias y Artes Cinematográficas.

Sin embargo, y mas allá de todos los premios que le falten por ganar, en el concierto del cine industrial de nuestros días, otra de las batallas importantes que tiene que lidiar una buena película tiene que ver con la cantidad de personas que la ven y el impacto que como obra cinematográfica puede conseguir. Así, Roma se estrena en territorio mexicano el 21 de noviembre de 2018 en cuarenta salas independientes que son parte de un circuito encabezado por la Cineteca Nacional.

Con relación a la distribución, la batalla que empezara en Cannes medio año antes Alfonso Cuarón y sus socios continuaría de manera inevitable en su propia tierra. Las dos compañías mas importantes de salas comerciales, Cinépolis con un $51 \%$ de las pantallas y Cinemex con $41 \%$ de participación del mercado (CANACINE 2018, 27), darían la espalda a una corrida en cartelera en cines de Roma ante la estrategia de distribución de la cinta en la plataforma de streaming.

Cinepolis, la principal cadena de exhibición de México, un poderoso jugador del entorno internacional con mas de 5,000 salas en el mundo y presencia en Estados Unidos, India, Europa, Centro y Sudamérica; dueño de 3,646 salas de las 7,106 que hay en el país (CANACINE, 2018, 27), se enfrenta al multipremiado director y a Netflix, y fija su posición con el siguiente comunicado en los medios: "A la opinión pública:

En Cinépolis nada nos gustaría más que poder exhibir la película ROMA de Alfonso Cuarón. La consideramos como una joya de la cinematografía moderna.

Desafortunadamente, ROMA fue vendida a Netflix cuyo modelo de negocio hasta ahora no ha contemplado la exhibición en salas de cine. En todo el mundo, las películas que se exhiben en salas de cine requieren un periodo durante el cual no estén disponibles en otras plataformas o canales. A estos periodos se les conoce coloquialmente como "ventanas". Tanto distribuidores como exhibidores trabajamos a nivel mundial con una ventana de exhibición en salas de cine que dura aproximadamente 90 días.
Desde el mes de mayo de este año sostuvimos conversaciones con Netflix con la mayor voluntad para exhibir ROMA en nuestras salas de cines respetando la ventana tradicional de exhibición. La ventana que Netflix ofreció, sin embargo, dista mucho de las prácticas comunes de la industria.

Invitamos a Netflix a posponer el estreno de ROMA en su plataforma para respetar la ventana tradicional de exhibición en salas de cine y Cinépolis estará feliz de estrenarla a partir del 29 de noviembre en todos nuestros cines a nivel nacional que dan cobertura a más de 75 ciudades en todos los estados de la República Mexicana. Además, ofrecemos que el $50 \%$ de la recaudación sea donada a organizaciones sociales vinculadas con la causa del trabajo doméstico". (Vértiz, 2018)

La respuesta del director no se hizo esperar criticando la posición de la distribuidora y argumentando que Netflix ya había cedido estrenando la cinta en salas de cine -algo que no suele hacer normalmente-, y dando a esta ventana tres semanas de duración antes de liberar la película en la plataforma digital, algo insuficiente para Cinépolis que exigía mínimo 90 días. Las quejas del realizador, a través de su cuenta de twitter, señalaban su descontento por las pocas pantallas que tendría Roma en México, las que comparaba con otros países donde tendría una exposición más relevante: "Quiero muchas más funciones en Mexico, tenemos todas las salas que hemos podido conseguir que, tristemente, son 40 . Para poner las cosas en perspectiva, en Polonia se exhibirá en 57 salas y en Corea del Sur en 50. ROMA está disponible a todas las salas que la quieran exhibir" (Vértiz, 2018).

Con ese mensaje, la producción y Cuarón, en un intento de llegar a más público y continuando con su exitosa campaña de relaciones públicas, ofrecieron gratuitamente Roma a universidades, centros culturales, cine clubes y escuelas utilizando en su cuenta de twitter el hashtag \#ROMATON, con el que se invitaba al público a compartir sus experiencias durante la proyección y comprometiéndose a hacer un donativo a una asociación vinculada con la lucha de las trabajadoras domésticas en México, un tema expuesto en el filme con alta resonancia social.

En un hecho sin precedentes, la cinta alcanzó las 140 pantallas en el país -todas al margen de los complejos de Cinepolis y Cinemex- y las 900 alrededor del mundo. Un registro nada despreciable para una pieza de cine de autor filmada en blanco y negro, hablada en castellano y mixteco por actores desconocidos (Beauregard 2018).

\section{Resultados, números y conclusiones.}

Con todo lo anterior era claro que continuaba la batalla y la confrontación entre dos maneras de entender las mecánicas de la industria cinematográficas y sus estrategias para conseguir ganancias con una película que, como era de esperarse, entraban de nuevo en controversia. La disputa iniciada, incluso antes de que la cinta de Cuarón fuera terminada, 
seguía en el centro de las discusiones sobre el futuro del cine y se adentraba en los terrenos de la imagen y las relaciones públicas.

El asunto no era más un diferendo sobre las ventanas de distribución y los tiempos que deberían durar las mismas. Ni siquiera se trataba ya de negociar cómo se repartirían los beneficios y cuánto debería tocarle a los involucrados en la ecuación. En el fondo, lo que estaba en juego era un asunto en el que se involucraban posiciones éticas y reputación. La visión de la tradición y el purismo frente a la lógica de tiempos nuevos con velocidades distintas y ofertas simultáneas. Un choque de propuestas en donde la búsqueda por explorar la posibilidad de desarrollar nuevas reglas para que, dos modelos de negocio antagónicos, y aparentemente irreconciliables, convivan y puedan salir ganando. Todo después de una conversación muy larga y una cantidad innumerable de artículos publicados en los medios al respecto.

Al final, y en concreto, Roma se estrenó en México en una colección de salas de un circuito alternativo que no permiten tener datos 0 indicadores objetivos de su asistencia con localidades agotadas y una extraordinaria recepción de público y crítica. Por otro lado, los números que sí conocemos, publicados por Netflix a través de los medios, algo poco común en su caso, resultan más que positivos.

Según la compañía, solamente en México habían visto la cinta de Cuarón hasta antes de la entrega de los Óscares, 3.6 millones de suscriptores de la plataforma, lo que convertía a Roma en la película en español mas vista en la historia del servicio y la colocaba muy cerca de los números récord de la producción norteamericana Birdbox, protagonizada por Sandra Bullock y que alcanzó los 4.8 millones como parte de un fenómeno también producido por Netflix (Beauregard 2018).

Entendiendo que las ventanas de explotación son diferentes, y que la comparación es poco más que ociosa, los resultados que obtuvo Roma en visualizaciones digitales la podrían colocar en el tercer lugar de las películas mexicanas mas vistas del año pasado en el país, y parecen proponernos varias reflexiones.

La primera y mas importante tiene que ver con la necesidad de entender que vivimos nuevos tiempos en los que seguir evaluando las situaciones desde lo blanco y lo negro parece poco afortunado. Las nuevas maneras de ver y experimentar lo audiovisual no son algo del futuro: están aquí y no solo se traducen en innovadoras formas de consumo, sino en estrategias $y$ modelos narrativos que impactan lo que hacemos y lo que haremos en los próximos años.

Si bien es cierto que la exhibición tradicional y el negocio de la salas de cine, en México particularmente, goza de una salud de hierro, también lo que sucede en las nuevas pantallas es parte de los temas que dominan la agenda. En la medida que entendamos eso, y en la inteligencia de que dejemos de buscar quién ganó la discusión alrededor del caso Roma, es que avanzaremos hacia un futuro en el que las experiencias y las historias sigan siendo lo mas importante.
En un lado de la moneda quedan los más de 170 premios en festivales de cine de todo el mundo que ganó la cinta de Alfonso Cuarón y la manera en que, a partir de esos reconocimientos se convirtió en un producto audiovisual atractivo y deseable para el público que asiste habitualmente a las salas de cine. En el otro lado está el entusiasmo que el origen y éxito mexicano de Roma despertó en el presidente de contenidos de Netflix, Ted Sandos, que anunció recientemente la apertura de oficinas de la compañía en el país para producir contenidos. Algo que, de manera directa o indirecta, impactará no sólo en lo que programará este nuevo jugador de la escena mediática en territorio nacional si no que modificará lo que se producirá desde nuestra industria y se exportará a todo el mundo.

Justo cuando las apuestas del mainstream siguen consiguiendo que un Blockbuster como Avengers Endgame rompa todos los récords de taquilla en su primer fin de semana en cines resulta que la temporada final de Game of thrones es un fenómeno de audiencia en las otras plataformas y pantallas. Al mismo tiempo. De modo simultáneo. Sin que uno de los consumos compita o impacte necesariamente en los alcances del otro. Sin que, al parecer, ir a ver una película a una sala de cine excluya que el mismo espectador, u otro, pueda ver a través del streaming otra cinta o una serie de ficción o documental.

Frente a todo esto el caso de Roma parece señalarnos, entre muchas otras cosas, que vivimos un momento histórico en el que el entretenimiento y el arte están buscando nuevas formas de encontrarse con sus públicos y que, de la inteligencia de los creadores, artistas y productores que desarrollan esos nuevos contenidos, depende el éxito o el fracaso. Sólo así, entendiendo que estamos en una evolución constante, es que se podrán conformar los nuevos paradigmas.

El futuro es hoy y no parece decantarse por una sola manera de entender la industria o un sólo modelo de negocio. Démosle tiempo al tiempo.

\section{Bibliografía}

ARTEAGA, Nelson; MASSE, Carlo y CASTRO, Pablo. Actores y poderes locales en la globalización. UNAM. Facultad de Ciencias Políticas y Administración Pública. $1^{a}$. Edición 2006. ISBN970-9785-45-1

BEAUREGARD, Luis Pablo, "Roma ha tenido en México mas de 3.6 millones de reproducciones en Netflix" El país

Febrero 6, 2019 https://elpais.com/cultura/2019/02/07/ actualidad/1549498295_379883.html

CANACINE. Cámara de la Industria Cinematográfica. Resultados definitivos 2018. Disponible en http:// canacine.org.mx/wp-content/uploads/2019/02/Resultadosdefinitivos'18-6.pdf

CASTELLS, Manuel. La era de la información. Economía, sociedad y cultura. Vol. 1. La sociedad red. México, Siglo XXI, 2004 (1996) ISBN-10: 9682321700

CINE Y TELE, "Francia reduce el tiempo entre las distintas ventanas de distribución en cine". Cine y Tele. Mayo 14,2019. http://www.cineytele.com/2019/01/10/ francia-reduce-el-tiempo-entre-las-distintas-ventanas-de- 
distribucion-de-cine/

CORRE CAMARA, "En 2018 creció el cine mexicano en producción y público". Corre cámara. Diciembre 1, 2018. http://www.correcamara.com.mx/inicio/int. php?mod=noticias_detalle\&id_noticia $=7285$

FERGUSON, Isabel, "Netflix anuncia oficina en la CDMX y nuevas inversiones en México" Expansión, Febrero 12, 2019. https://expansion.mx/tecnologia/2019/02/12/netflixanuncia-oficina-en-la-cdmx-y-nuevas-inversiones-enmexico

GARCÍA CANCLINI, Néstor. La globalización imaginada. México, Paidós, 1999.ISBN-10: 968853434X

GARCÍA CANCLINI, Néstor. De lo local a lo global: perspectivas desde la antropología. México, UAM, Unidad Iztapalapa, División de Ciencias Sociales y Humanidades, Departamento de Antropología, 1994. ISBN-10: 9503409888

GARCÍA CANCLINI, Néstor y SÁNCHEZ RUIZ, Enrique (Comp.). Situación actual y perspectivas de la industria cinematográfica en México y en el extranjero. Guadalajara, Universidad de Guadalajara, Instituto Mexicano de Cinematografía, 2006.ISBN: 970-27-0937-7

GIDDENS, Anthony. Un mundo desbocado. Los efectos de la globalización en nuestras vidas. México: Taurus,1999. ISBN-10: 9681907949

GÍMENEZ Gilberto. Estudios sobre la cultura y las identidades sociales. CONACULTA, México, 2007. ISBN: 978-968-5087-9 -9

HUERTA, César. "Crece la industria del cine y genera mas empleos". El Universal, Marzo 23, 2019 https://www. eluniversal.com.mx/espectaculos/crece-la-industria-delcine-y-genera-mas-empleos

Instituto Mexicano de Cinematografía. Anuario estadístico de cine mexicano 2017. México 2017. Disponible en http://mptests.info/wp-content/uploads/ CINEMEXICANO/ANUARIOESTADISTICO/ANUARIO_ ESTADI_STICO_DE_CINE_MEXICANO_2017_PDF_HD_ DEF.pdf

Instituto Mexicano de Cinematografía. Anuario estadístico de cine mexicano 2016. México 2016. Disponible en http://mptests.info/wp-content/uploads/ CINEMEXICANO/ANUARIOESTADISTICO/Anuario_ estadistico_de_cine_mexicano_2016.pdf

KAPLAN̄, Marcos. Estado y globalización. UNAM, Instituto De Investigaciones Jurídicas, 2002. ISBN:986-369952-9

LULL, James. Supercultura para la Era de la Comunicación. En J. Lull (ed.), Culture in the Communication Age. London: Routledge, 2000.ISBN, 0415221161

MARTEL Frederic. Cultura Mainstream. Editorial Taurus. Madrid. 2011. ISBN-10: 8430608036

MARTINEZ Carla, "Netflix, Calro video y Blim ganan clientes en México" El Universal, Mayo 6, 2019. https:// www.eluniversal.com.mx/cartera/indicadores/netflix-clarovideo-y-blim-ganan-clientes-en-mexico

SÁNCHEZ RUIZ, Enrique. Cine y Globalización en México. El desplome de una industria cultural. En Comunicación y Sociedad (DECS, Universidad de Guadalajara), num.33, mayo-agosto 1998, pp.47-91.

THOMPSON, John. Los media y la modernidad. Barcelona, Paidós, 1998.ISBN-84-493-0578-0

VERTIZ, Columba, "Cinépolis da su postura de porqué no exhibe Roma" Proceso, Noviembre 22, 2018. https:// www.proceso.com.mx/560735/cinepolis-da-su-postura-depor-que-no-exhibe-roma. 